\title{
Endogenous Optimal Currency Areas: the Case of the Central African Economic and Monetary Community
}

\section{Fabrizio Carmignani*}

School of Economics, The University of Queensland, Brisbane, Australia

* Corresponding author: Fabrizio Carmignani, School of Economics, The University of Queensland, Brisbane, QLD 4072, Australia. Telephone: +61 73365 6619. Fax: +61 73365 7299. E-mail: f.carmignani@uq.edu.au

\section{Abstract}

The Central African Economic and Monetary Community (CAEMC) has been a monetary union for several decades now. According to the hypothesis of endogenous optimal currency areas (OCAs), the degree of business cycle

20 synchronisation across its member states should be significantly higher today than forty years ago. This paper examines cycle synchronisation along three different statistical dimensions and shows that (i) synchronisation has remained low throughout the period 1960-2007, but (ii) it has marginally increased over time. These findings have important implications for the design of the economic integration process in Africa. A chronology of business cycles in CAEMC countries is provided.

JEL classification: E32, E39, F15, O10

\section{Introduction}

Monetary unification nowadays is a key objective of many African regional economic communities (REC) ${ }^{1}$. As a consequence, a lively debate on

${ }^{1}$ UNECA (2004) provides a comprehensive assessment of regional integration in Africa. Out of fourteen RECs, nine target a complete monetary and economic unification, albeit the time horizon differs across RECs. The creation of a continental monetary and economic union in 2023-28 is also one of the key objectives of the African Union.

(C) The author 2009. Published by Oxford University Press on behalf of the Centre for the Study of African Economies. All rights reserved. For permissions, please email: journals.permissions@oxfordjournals.org 
whether specific regional clusters of African countries configure as optimal currency areas (OCAs) is currently ongoing (see for instance Fielding et al., 2004; Carmignani, 2006; Karras, 2007; Agbeyegbe, 2008; Bangake, 2008; Tapsoba, 2009). Most of the existing research focuses on the ex-ante assessment of conditions for an OCA, thus neglecting the possible endogeneity effect of currency unification ${ }^{2}$ : even if they are not met ex-ante, the conditions for an OCA could still be achieved ex-post as a result of the formation of the currency union. The purpose of this paper is to fill the gap in the literature. Its relevance is twofold. From an academic perspective, the existence in Africa of currency unions that did not necessarily meet the OCA conditions at the time of their formation creates the opportunity for a direct test of the endogeneity effect. From a policy-making perspective, the finding that currency unions are endogenous would imply that quick monetary integration is a worthwhile option even if shocks are asymmetric across countries in the same region (as is often the case in Africa; see, for instance, Khamfula and Huizinga, 2004; Buigut and Valev, 2005; Houssa, 2008). On the contrary, if currency unions were not endogenous, then a speedy monetary unification would not benefit countries collectively and might therefore jeopardise the whole regional integration initiative.

The idea that an OCA might be endogenous has gained momentum following the seminal work of Frankel and Rose (1998). They find that, in a panel of OECD economies, the intensity of cross-country bilateral trade increases the bilateral correlation of a measure of economic activity. This result is combined with evidence provided by Rose (2000) that currency unions increase bilateral trade in a standard gravity model framework. Thus, an OCA would be endogenous in the sense that, when a currency union is formed, trade integration between its members increases, which in turn makes their business cycles more synchronised. In fact, deeper trade integration might not be the only channel through which monetary unions self-validate. Corsetti and Pesenti (2002) propose a model where pricing strategies in a monetary union induce business cycle synchronisation even in the absence of an effect on bilateral trade. Easier technological spillovers (in the spirit of Coe and Helpmann, 1995) might also contribute to greater synchronisation in the wake of monetary integration.

${ }^{2}$ A notable exception is Fielding and Shields (2005). Differences between their paper and this paper are discussed below. Tapsoba (2009) also provides evidence on endogeneity by adding a dummy variable for membership in a monetary union to the list of regressors in his analysis of the determinants of the synchronisation of cycles between pairs of countries. 
Much of the empirical literature on the endogeneity hypothesis follows the track set by Frankel and Rose (1998) and Rose (2000) and uses panel regressions and gravity models to estimate the effects of monetary unions in global data sets. ${ }^{3}$ Results are not always unanimous. Fidrmuc (2004) extends the basic specification of Frankel and Rose (1998) and finds that synchronisation increases only to the extent that intra-industry trade grows. Belke (2007) instead links business cycle synchronisation to similarities in sectoral structures. Barro and Tenreyro (2007) use a newly developed instrumental variables procedure to control for the possible 90 endogeneity of exchange rate arrangements and economic variables. They find, in line with Rose (2000), that a common currency enhances trade. ${ }^{4}$ However, they also find that a common currency decreases co-movements of shocks to real GDP, which is at odds with the endogeneity hypothesis. Tapsoba (2009) estimates the determinants of synchronisation in a large group of African countries. He finds that bilateral trade integration increases synchronisation, albeit the effect is quantitatively smaller than what is usually reported for industrial economies. After controlling for bilateral trade, the residual effect of monetary unions on synchronisation is found to be statistically insignificant.

100 This paper looks at the issue from a different perspective. Instead of estimating panel and/or gravity models on large samples of countries, it tests directly the endogeneity of a specific currency union: the Central African Economic and Monetary Community (CAEMC, perhaps better known by its French name Communauté Economique et Monétaire de l'Afrique

105 Centrale). The CAEMC is indeed a very interesting case study. The currency union was set up during the colonial period. After independence, the members of the community decided to retain the basic monetary and exchange rate arrangements of the colonial times. This cluster of six countries has therefore been a currency union for several decades now. A

110 straightforward test of endogeneity can be therefore implemented by computing measures of business cycle synchronisation across CAEMC countries and then checking whether or not they tend to increase over time. This will require the preliminary identification and dating of the business cycles of CAEMC countries. The resulting chronology represents

${ }^{3}$ Rose (2008) provides a meta-analysis of existing empirical evidence focusing on the European Monetary Union.

4 The trade effects of currency unions have been estimated by a large number of studies. Rose (2004) surveys this strand of the literature and provides meta-estimates of the elasticity of bilateral trade to participation into a currency union. 
an important innovative contribution of this paper given that no such thing is available for CAEMC countries in the literature ${ }^{5}$.

Methodologically, the exercise proposed in this paper is similar to the one undertaken by Savva et al. (2007) and Darvos and Szapary (2008). They both look at whether synchronisation between the EMU and the new/perspective EU members is increasing over time. Their sample is therefore very different from the one used in this paper. Moreover, since new/perspective EU members are not yet EMU members, their analysis cannot really be interpreted as a test of the endogeneity of an OCA. Fielding and Shields (2005), on the contrary, specifically look at whether currency unions in West Africa have increased macroeconomic integration in the sub-region. Among the measures of macroeconomic integration that they consider are bilateral trade intensity and bilateral shock correlations. In this respect, their work provides evidence on whether or not West Africa is an endogenous OCA. Nevertheless, there are some important differences between their paper and this paper. First of all, they do not identify and date business cycles to assess synchronisation across countries. Their test is based on the estimation of panel specifications similar to those of Frankel and Rose (1998) and Rose (2000). Furthermore, they treat the whole of the African Financial Community (CFA) as a unique monetary union. In fact, the CFA zone consists of two different unions: the West African Economic and Monetary Union (WAEMU) and the CAEMC. In spite of common origins and many similarities, the WAEMU and the CAEMC have different policy-making organs (including different central banks), different trade regimes (there are no free trade arrangements between the two unions) and a different pace of integration (as documented in UNECA, 2004). In conducting a test of endogeneity, it is therefore important to distinguish between the two groups. The CAEMC is retained as the object of investigation in this paper because it has received less attention in previous works than the WAEMU.

The main result of this paper can be summarised as follows. The various indicators examined suggest that synchronisation across CAEMC countries is generally quite low, but somewhat increasing over time. Nevertheless, this increase is weak in economic and statistical terms, in line with the weak progress on regional trade integration and macroeconomic policy harmonisation/convergence.

The rest of this paper is organised as follows. Section 2 presents the chronology of recessions and expansions in CAEMC countries. Section 3

${ }^{5}$ To the best of my knowledge. 
looks at the evolution of business cycle synchronisation in the region. Section 4 provides a discussion of the key results in light of the endogenous OCA hypothesis. Section 5 draws some policy conclusions and sets the lines for future research.

\section{Detecting and dating business cycles}

\subsection{Methodology for the identification and dating of business cycles}

The assessment of synchronisation requires the preliminary identification and dating of business cycles. In a nutshell, this amounts to determining the turning points in the series of a variable that can be regarded as a reliable broad-based measure of economic activity (i.e., GDP or industrial production). Starting with the seminal work of Burns and Mitchell (1946), various algorithms for the determination of turning points have been proposed in the literature (see, for instance, the recent contributions of Artis et al., 2004; Proietti, 2005; Harding and Pagan, 2006). Two main approaches can be identified. One goes under the name of classical cycle

180 and dates back to the work of Bry and Boschan (1971). The classical cycle selects its turning points on the basis of an absolute decline (or rise) of the reference series. The other approach is called deviation (or growth) cycle. In this case, the original reference series is first decomposed into a trend and a cyclical component by means of a filtering procedure.

185 Then turning points are identified on the basis of the sequential oscillations of the cyclical component.

When the reference series is relatively persistent and rarely declining in absolute values (as was the case of GDP series in Europe in the early post-war decades, for instance), then the deviation cycle appears to be ana-

190 lytically more valuable. However, in the deviation cycle, the selection of turning points might be sensitive to the choice of the filtering procedure, so that different procedures generate different chronologies. The pragmatic methodological choice made in this paper is to present results based on both approaches. For the deviation cycle, the filter used to detrend the

195 original reference series is the one proposed by Hodrick and Prescott (1997), HP from now on. ${ }^{6}$

${ }^{6}$ Results obtained from the Baxter-King filter (Baxter and King, 1999) are substantially the same as those obtained from the HP filter. A short technical discussion of filtering procedures can be found in the Appendix of the working paper version of this article 
The reference series used for identification and dating is log real GDP $(y)$. A crucial difference between dating the business cycle of African countries and of industrial countries is that for African countries GDP series are normally available only on an annual basis. In contrast, for industrial countries quarterly, if not monthly, series are available. Given that most of the existing literature focuses on industrial economies, the algorithms are generally designed to fit quarterly or monthly data. Some modifications are therefore necessary to apply them to annual data.

This paper makes use of a simplified version of the algorithm presented by Artis et al. (2004, 2005). In short, the algorithm is based on the following representation. At any point in time $t$ the economy is either in recession $\left(R_{t}\right)$ or in expansion $\left(E_{t}\right)$. The state (recession or expansion) observed at time $t$ continues at time $t+1$ unless at time $t+1$ a termination sequence occurs. If a termination sequence occurs, then $t$ is a turning point (peak of an expansion or trough of a recession), and $t+1$ is the first period of a new cyclical phase.

In the classical cycle, the expansion termination sequence (ETS) and the recession termination sequence (RTS) are defined as:

$$
\begin{aligned}
& \mathrm{ETS}_{t}=\left\{\Delta y_{t+1}<-c\right\} \\
& \mathrm{RTS}_{t}=\left\{\Delta y_{t+1}>c\right\}
\end{aligned}
$$

where $\Delta$ is the first-difference operator (so that $\Delta y$ is the growth rate of real GDP) and $c$ is a positive constant. The purpose of introducing $c$ is to make sure that the algorithm isolates only major fluctuations, thus making the dating process more robust. In the application below, we follow Artis et al. $(2004,2005)$ and set $c=0.005(=0.5 \%)$. In words, equations (1) and (2) imply that time $t$ is the peak of an expansion (the trough of a recession) if at time $t+1 y$ decreases (grows) by more than $0.5 \%$ relative to year $t$. Otherwise, the expansion (recession) continues in $t+1$. $^{7}$

In the deviation cycle, ETS and RTS are slightly modified to assure that the peak of an expansion (the trough of a recession) does not correspond to a negative (positive) value of the cyclical component of $y$. Therefore, let the

7 The magnitude of fluctuations in CAEMC countries is relatively larger than in European countries. This might suggest setting $c$ above the $0.5 \%$ threshold value used by Artis et al. $(2004,2005)$. As a sensitivity check, the values 0.75 and $1 \%$ have also been used. Results are not qualitatively different from those reported in Tables 1 and 4 . The additional results obtained from values of $c=0.75$ and $1 \%$ are available from the author upon request. 
cyclical component be denoted by $y^{c}$, and then we have:

$$
\begin{gathered}
\operatorname{ETS}_{t}=\left\{\left(y_{t}^{c}>0\right) \cap\left(\Delta y_{t+1}<-c\right)\right\} \\
\operatorname{RTS}_{t}=\left\{\left(y_{t}^{c}<0\right) \cap\left(\Delta y_{t+1}>c\right)\right\}
\end{gathered}
$$

245 Thus, in the deviation cycle, year $t$ is the peak of an expansion (the trough of a recession) if the cyclical component of real GDP in the year $t+1$ decreases (grows) by more than $0.5 \%$ relative to the year $t$, and the cyclical component in the year $t$ is positive (negative). Otherwise, the expansion (recession) continues in the year $t+1$.

\subsection{A business cycle chronology for CAEMC countries}

The algorithm is applied to log real GDP series of the six CAEMC African countries: Cameroon, Central African Republic (CAR), Chad, Congo-

255 Brazzaville, Equatorial Guinea and Gabon. The sample period is 1960-2007 for all the countries with the exception of Equatorial Guinea, for which the starting date is 1985. GDP data are taken from the World Bank Development Indicators and the Official Statistics of the Banque Centrale des Etats de l'Afrique Centrale.

260 The annual chronology for each country is reproduced in the working paper version of this article (Carmignani, 2009, available on-line). Table 1 reports some key summary statistics that help characterise the cyclical fluctuations in the six members of the monetary union. All durations are expressed in years.

265 A few stylised facts are worth noting. First of all, the classical cycle and the deviation cycle generate significantly different chronologies. The proportion of time in expansion is considerably longer in the classical cycle. This is to be expected, given that the definition of recession in the classical cycle (a decrease in the absolute level of log real GDP) corresponds to a rather unli-

270 kely event in most countries. Furthermore, turning points are more frequent in the deviation cycle. As a consequence, the average duration of a cycle is longer in the classical version. This reflects a significantly longer duration of expansions, since recessions tend to be longer in the deviation cycle.

Second, the classical cycle chronology (whose details can be found in 275 Carmignani (2009)) reveals some common patterns across countries. All countries, with the exception only of Chad, go through at least one period of prolonged expansion, either at the beginning of the sample period (CAR, Congo, Gabon) or towards the end (Cameroon and Equatorial Guinea). Furthermore, the last years of the sample, characterised by booming oil prices, mark the beginning of a phase of expansion 
Table 1. Summary statistics of business cycles in CAEMC countries

\begin{tabular}{|c|c|c|c|c|c|c|}
\hline & Cameroon & CAR & Chad & Congo & Eq Guinea & Gabon \\
\hline \multicolumn{7}{|l|}{ Classical cycle } \\
\hline Total turning points & 8 & 12 & 18 & 12 & 8 & 10 \\
\hline $\begin{array}{l}\text { Average duration of a } \\
\text { cycle }\end{array}$ & 12 & 8 & 5.33 & 8 & 7 & 9.6 \\
\hline $\begin{array}{l}\text { Average duration of a } \\
\text { recession }\end{array}$ & 2.75 & 2.17 & 1.44 & 1.5 & 1 & 1.8 \\
\hline $\begin{array}{l}\% \text { of time in expansion } \\
\text { Deviation cycle }\end{array}$ & 77.1 & 72.9 & 72.9 & 81.2 & 85.7 & 81.2 \\
\hline Total turning points & 17 & 20 & 19 & 16 & 11 & 14 \\
\hline $\begin{array}{l}\text { Average duration of a } \\
\text { cycle }\end{array}$ & 5.6 & 4.8 & 5.1 & 6 & 5.1 & 6.8 \\
\hline $\begin{array}{l}\text { Average duration of a } \\
\text { recession }\end{array}$ & 2.7 & 2.2 & 2.2 & 1.9 & 2.5 & 3 \\
\hline$\%$ of time in expansion & 50 & 54.1 & 54.1 & 68.7 & 46.2 & 56.2 \\
\hline
\end{tabular}

Notes: Reference series is log real GDP for each country (annual data). Sample period is 1960-2007 for each country with the exception of Equatorial Guinea, for which the starting date is 1985 . For details on the dating algorithm and the full chronology, see Carmignani (2009).

for the region as a whole. The pattern is, however, much less clear in the deviation cycle chronology, where episodes of prolonged expansion are dispersed over the whole of the sample period and the 2000s are not necessarily associated with an expansion at the regional level.

Third, a cursory glance at the sequence of turning points and phases suggests that business cycles are not very much synchronised. In the classical cycle chronology, the six countries happen to be in the same cyclical phase in only sixteen out of a total of forty-eight years. This common cyclical phase is always an expansion; that is, countries are never contemporaneously in a recession. Moreover, there are only two years when more than two countries change the cyclical phase in the same direction: in 1987, when four countries reach a trough, and in 1988, when three countries reach the peak of an expansion. Cycles look even less synchronised in the deviation cycle chronology, where all countries happen to be in the same cyclical phase only twice (1974 and 1998) in forty-eight years. However, more frequent turning points also imply that countries turn the cyclical phase in the same direction more often than in the classical cycle chronology.

Finally, it is interesting to look at cyclical dynamics around 1994, the year of the devaluation of the franc CFA. The chronologies indicate that prior to the devaluation Cameroon went through a phase of prolonged recession. For the 
other countries, in contrast, the late 1980s and early 1990s were a period of volatility, with frequent turning points and short-lasting cycles. Nevertheless, most of the region was in a recession in 1993 and entered an expansion between 1994 and 1995, at least according to the deviation cycle

325 chronology. This suggests that the devaluation might have effectively boosted exports and the macroeconomic performance of CAEMC countries in the short-term. However, it does not imply that cycles across countries have become systematically more synchronised after the devaluation.

\section{Business cycle synchronisation in the CAEMC region over time}

\subsection{Measuring business cycle synchronisation}

335 The degree of synchronisation of the business cycles of the CAEMC countries is measured along three statistical dimensions. The first one is the intensity of co-movements across countries: the cross-country contemporaneous bilateral correlations of $y, y^{\mathrm{c}}, \Delta y$ and $\Delta y^{\mathrm{c}}$ are computed over four overlapping subperiods (1960-80, 1970-90, 1980-2000, 1987-2007). An increase in corre-

340 lation coefficients over time, meaning that synchronisation is growing, can be taken as evidence in support of the endogeneity hypothesis. By Darvas and Szapary (2008), in addition to the contemporaneous correlation, the leads and lags that maximise the bilateral correlations are also calculated. From an OCA perspective, zero or small lags/leads are optimal. Therefore, a pro-

345 gressive decrease of leads/lags is also to be interpreted as evidence that the CAEMC is a self-validating monetary union.

The second dimension pertains to the statistical properties of business cycles. The first- order autocorrelation (AC) and the standard deviation of each of the four series $\left(y, y^{\mathrm{c}}, \Delta y\right.$ and $\left.\Delta y^{\mathrm{c}}\right)$ are computed for each of the six

350 countries over each of the four sub-periods (1960-80, 1970-90, 19802000, 1987-2007). The first-order AC measures the persistence of the cycle, whereas the standard deviation measures its volatility. The logic underlying the use of these two measures is that business cycles cannot be synchronised if they are very dissimilar in terms of their basic statistical properties.

355 Therefore, a progressive reduction in the cross-country dispersion of AC and/or standard deviation will be interpreted as an increase in synchronisation.

The third dimension is the correspondence of cyclical phases across countries. If countries happen to be in the same phase at the same time, 360 then the delegation of monetary policy to a regional central bank does 
not compromise the stabilisation of the national cycle. If instead countries go through different phases at different times, a unique regional monetary policy cannot contemporaneously accommodate the stabilisation needs of all union members. As a consequence, the discordance of cyclical phases makes the monetary union suboptimal. The statistical measure of concordance used in this paper follows Harding and Pagan $(2001,2006)$. Let $S_{i t}$ be 1 if country $i$ is in recession at time $t$, and zero otherwise. Analogously, $S_{j t}$ is equal to 1 if country $j$ is in recession at time $t$. Then the simple matching similarity coefficient (standard concordance index) between the two countries is as follows:

$$
I_{i f}=\frac{1}{T} \sum_{t=1}^{T}\left[S_{i t} S_{j t}+\left(1-S_{i t}\right)\left(1-S_{j t}\right)\right] \quad \text { where } t=1, \ldots, T
$$

As discussed by Harding and Pagan (2001), the index (5) is upwards biased if cycles are significantly asymmetric, that is, if countries spend much longer time in one cyclical phase than in the other. To avoid this problem, the index has to be mean-corrected. If $E\left[S_{i t}\right]$ and $E\left[S_{i=j t}\right]$ denote the expected values of $S_{i t}$ and $S_{j t}$, respectively, then the mean- corrected concordance index is written as:

$$
I_{i j}^{*}=\frac{2}{T} \sum_{t=1}^{T}\left(S_{i t}-E\left[S_{i t}\right]\right)\left(S_{i t}-E\left[S_{j t}\right]\right)
$$

Both, $I_{i j}$ and $I_{i j}^{*}$ are computed for each pair of countries in CAEMC over each of the four sub-periods. Again, increasing values of the two indexes over time will be taken as evidence in support of the endogeneity hypothesis.

\subsection{Evolution of business cycle synchronisation in CAEMC}

\subsubsection{Evidence from bilateral correlations}

Table 2 reports the average contemporaneous correlation coefficient for each country, in each sub-period and for each variable. For the generic country $i$, this average correlation coefficient is simply the average of the bilateral contemporaneous correlations between $i$ and all of the other countries in the region. ${ }^{8}$ The column labelled 'Average' reports the

${ }^{8}$ The full set of bilateral correlation coefficients and standard deviations for each reference variable and each sub-period is available upon request from the author. 
Table 2. Average bilateral correlation coefficients and lag/lead

\begin{tabular}{|c|c|c|c|c|c|c|c|c|}
\hline & CMR & CNG & GBN & GNQ & RCA & TCD & Average & Lag/Lead \\
\hline \multicolumn{9}{|c|}{ Log-level of GDP (y) } \\
\hline $60 \_80$ & 0.694 & 0.741 & 0.783 & n.a & 0.786 & 0.219 & 0.645 & \\
\hline 70_90 & 0.739 & 0.708 & 0.534 & 0.737 & 0.762 & 0.540 & 0.670 & \\
\hline 80_00 & 0.429 & 0.672 & 0.632 & 0.675 & 0.709 & 0.710 & 0.638 & \\
\hline 87_07 & 0.758 & 0.863 & 0.754 & 0.879 & 0.777 & 0.839 & 0.812 & \\
\hline \multicolumn{9}{|c|}{ First difference of log-level of GDP $(\Delta y)$} \\
\hline $60 \_80$ & -0.129 & -0.108 & 0.081 & n.a & 0.104 & 0.128 & 0.015 & 1.7 \\
\hline 70_90 & 0.049 & 0.028 & -0.001 & 0.093 & 0.057 & 0.157 & 0.064 & 2.1 \\
\hline 80_00 & 0.175 & 0.030 & 0.076 & 0.027 & 0.114 & 0.073 & 0.083 & 1.5 \\
\hline 87_07 & 0.229 & 0.089 & 0.114 & 0.100 & 0.157 & 0.128 & 0.136 & 1.1 \\
\hline \multicolumn{9}{|c|}{ Detrended GDP $\left(y^{c}\right)$} \\
\hline $60 \_80$ & -0.049 & -0.026 & 0.115 & n.a & 0.130 & 0.233 & 0.081 & 1.8 \\
\hline 70_90 & -0.012 & -0.119 & 0.059 & 0.035 & 0.127 & 0.242 & 0.055 & 1.9 \\
\hline 80_00 & 0.176 & 0.028 & 0.243 & 0.065 & 0.124 & 0.240 & 0.146 & 1.3 \\
\hline 87_07 & -0.039 & 0.062 & 0.147 & 0.054 & -0.033 & 0.089 & 0.047 & 1.2 \\
\hline \multicolumn{9}{|c|}{ First difference of detrended GDP $\left(\Delta y^{\mathrm{C}}\right)$} \\
\hline $60 \_80$ & -0.110 & 0.004 & -0.025 & n.a & 0.069 & 0.102 & 0.008 & 1.8 \\
\hline 70_90 & -0.093 & 0.008 & -0.043 & -0.023 & 0.024 & 0.172 & 0.007 & 1.7 \\
\hline 80_00 & 0.007 & -0.040 & 0.089 & -0.069 & 0.060 & 0.079 & 0.021 & 1.3 \\
\hline 87_07 & 0.019 & -0.021 & 0.164 & -0.084 & 0.077 & 0.104 & 0.043 & 1.3 \\
\hline
\end{tabular}

Notes: For each country and each variable, the average bilateral contemporaneous correlation coefficient is computed as the average over each sub-period of the bilateral contemporaneous correlation coefficients between that country and all of the countries in the group. The column labelled 'average' shows the average of all bilateral correlation coefficients computed in each sub-period. In the last column, the average lag/lead is computed as the average of the lags/leads that maximise the bilateral correlation coefficients in each sub-period. CMR, Cameroon; CAR, Central African Republic; TCD, Chad; CNG, Congo; GBN, Gabon; GNQ, Equatorial Guinea.

430 average of all bilateral correlation coefficients calculated for a specific subperiod. The last column of the table reports the average of the lag/lead that maximises the bilateral correlations.

As expected, the bilateral correlations of $y$ are the highest. However, since they tend to be influenced by the trend of real GDP, they are also the least 435 informative in terms of business cycle synchronisation. Therefore, the rest of the discussion focuses on the other three variables.

For each of the other three reference series, the bilateral correlations are rather low and hardly significant in statistical terms. This is evident from a comparison with bilateral correlations computed for EMU member states, 
which range between 0.4 and $0.65^{9}$. In this respect, there is no evidence of systematic cyclical co-movement across countries in the CAEMC currency union. However, when comparing the first sub-period (1960-80) with the last two sub-periods (1980-2000 and 1987-2007), some mild increase in the size of correlation coefficients is observed. In particular, for both $\Delta y$ and $\Delta y^{c}$, the average bilateral correlation is considerably higher in the last sub-period than in the first sub-period. For the other reference variable, $y^{\mathrm{c}}$, the highest average bilateral correlation is observed in the third sub-period. Moreover, for ten out of fifteen country pairs, the bilateral correlation coefficient of $\Delta y$ and $y^{c}$ is higher in 1987-2007 than in 1960-80; for nine out of fifteen the bilateral correlation coefficient of $\Delta y^{c}$ is higher in 1987-2007 than in 1960-80. One can therefore argue that, while remaining always rather low, the degree of co-movement of cyclical fluctuations has to some extent increased over time in the CAEMC area. ${ }^{10}$

The evidence from the last column of the table is consistent with the previous observations. Bilateral correlations are generally maximised for a non-zero lag, which implies a rather low degree of co-movement across countries. However, there is a generalised, mild tendency for lag/lead to decrease over time. In particular, the lag/lead decreases between the last and the first sub-period for ten out of fifteen country pairs when the reference variable is $\Delta y$, for eleven out of fifteen country pairs when the reference variable is $y^{c}$ and for nine out of fifteen country pairs when the

9 Average bilateral correlations between EMU members are as follows. For the variable $\Delta y$ : 0.406 in 1960-80, 0.504 in 1970-90, 0.496 in 1980-2000 and 0.554 in 1987-2007. For the variable $y^{\text {c. }}: 0.426$ in $1960-80,0.570$ in $1970-90,0.622$ in $1980-2000$ and 0.647 in $1987-2007$. For the variable $\Delta y^{\mathrm{c}}: 0.357$ in $1960-80,0.466$ in $1970-90,0.531$ in $1980-$ 2000 and 0.653 in 1987-2007.

10 The statistics reported in Table 2 for $y^{\mathfrak{c}}$ and $\Delta y^{\mathrm{c}}$ are obtained from a Hodrick-Prescott trend-cycle decomposition of $y$ with a smoothing parameter set according to the algorithm of Ravn and Uhlig (2002). The synchronisation patterns observed from Table 2 hold when a fixed value of 100 is chosen for the smoothing parameter (as originally proposed by Hodrick and Prescott, 1997). Let $y^{c 100}$ be the cyclical component computed using a smoothing parameter equal to 100 and $y c^{\mathrm{RU}}$ the cyclical component computed using the Ravn and Uhlig algorithm. The two cyclical components indeed look remarkably similar. The average correlation between $y^{c 100}$ and $y c^{\mathrm{RU}}$ is 0.8 , whereas the average correlation between $\Delta y^{c 100}$ and $\Delta y c^{\mathrm{RU}}$ is 0.9 . The series $y^{c 100}$ and $y c^{\mathrm{RU}}$ are in the same cyclical phase on average $87 \%$ of the time. The only substantive change when using a smoothing parameter equal to 100 is that the peak in the synchronisation of $y^{c}$ series is observed in the second sub-period (1970-90) and not in the third sub-period (1980-2000). Correlation coefficients are also marginally higher when setting the smoothing parameter equal to 100 , but their trend remains only weakly upwards sloping. 
reference variable is $\Delta y^{\mathrm{c}}$. On the other hand, an increase in the lag/lead is rare, whatever reference variable is considered.

\title{
3.2.2 Evidence from first-order AC and volatility
}

The extent to which the business cycles of CAEMC countries display similar statistical properties is assessed from the data in Table 3. For each sub-period, the table shows the dispersion across CAEMC countries of (i) the first-order autocorrelation coefficient (AC) and (ii) the volatility 490 (standard deviation) of each of the four reference variables. Dispersion is measured by the standard deviation of each variable's distribution across countries. In fact, because data for Equatorial Guinea became available only after 1985, the dispersion is computed for the group of the five remaining CAEMC countries until 1985 and for the full group of six countries afterwards. To make the analysis more robust, the table also

Table 3. Variation across countries in first-order auto-correlation and volatility of cyclical phases

\section{First-order autocorrelation (AC) Volatility (standard deviation)}

\begin{tabular}{|c|c|c|}
\hline 60_80 & 70_90 & 8000 \\
\hline
\end{tabular}

Log-level of GDP $(y)$

\begin{abstract}
All countries
\end{abstract}
$\begin{array}{ll}0.182 & 0.084\end{array}$

0.108

0.047

0.182

0.079

$0.109 \quad 0.038$

0.182

0.143

0.205

0.330

First difference of log-level of GDP $(\Delta y)$

All countries

0.133

0.412

0.393

Excluding GNQ

0.133

0.311

0.410

0.331

0.356

0.036

0.036

0.037

0.059

0.096

Detrended GDP $\left(y^{\mathrm{c}}\right)$

All countries

0.253

0.339

0.199

0.111

0.024

$0.203 \quad 0.090$

0.024

0.026

0.026

0.033

0.040

First difference of detrended GDP $\left(\Delta y^{\mathrm{C}}\right)$

\begin{tabular}{lllllllll} 
All countries & 0.127 & 0.308 & 0.152 & 0.081 & 0.026 & 0.027 & 0.021 & 0.030 \\
Excluding GNQ & 0.127 & 0.229 & 0.169 & 0.085 & 0.026 & 0.028 & 0.016 & 0.022 \\
\hline
\end{tabular}

Notes: For each reference variable and each sub-period the table reports the variation of

$A C$ and standard deviation across the CAEMC members. Variation is measured by the standard deviation of AC and standard deviation across countries in each sub-period. For each reference variable, the first row (labelled 'All countries') refers to the variation measured across all CAEMC members; the second row (labelled 'Excluding GNQ') refers to the variation measured across CAEMC members excluding the Equatorial Guinea. The full set of $A C$ and standard deviation data by country and sub-periods is given in Carmignani (2009). 
reports the dispersion for the sub-group of five countries that excludes Equatorial Guinea in all sub-periods. ${ }^{11}$

Consider AC first. Between the first and last sub-periods, there is a decrease in dispersion for three out of the four reference variables. Focusing on the three variables that are more informative for business cycle analysis $\left(\Delta y, \Delta y^{\mathrm{c}}\right.$ and $\left.y^{\mathrm{c}}\right)$, the general pattern is characterised by an increase in dispersion between the first and the second sub-period, followed by a decrease in subsequent sub-periods. However, only for the two detrended series, $\Delta y^{c}$ and $y^{c}$, is the observed reduction in the third and fourth sub-periods sufficient to bring dispersion below its initial level. The dynamics of dispersion are qualitatively similar when Equatorial Guinea is removed from the sample. That is, the increase in dispersion between 1960-80 and 1970-90 does not appear to be driven by the inclusion of Equatorial Guinea in the CAEMC group.

Turning to standard deviation, its dispersion across countries is generally increasing between the first and the last sub-period. With the exception of $y$, however, this increase is not particularly strong. Moreover, the pattern is not monotonic and a decrease in dispersion is observed between the second and the third sub-period. It is only in the course of the last subperiod that countries become significantly more different in terms of the volatility of their national cycles. Two complementary factors could account for these growing differences. One is the increasing volatility of international primary commodity prices. Given the high dependence of CAEMC economies on primary commodity exports, more volatile international prices imply more volatile external shocks. The other factor is the transformation of Equatorial Guinea into a very fast growing oil economy at the end of the 1990s. As a matter of fact, if Equatorial Guinea is excluded from the sample, the dispersion of the standard deviation turns out to be lower in the last sub-period than in the first subperiod, even though still increasing between 1980-2000 and 1987-2007.

Overall, the analysis of the statistical properties of business cycles provides rather ambiguous evidence. In terms of their persistence (as measured by $\mathrm{AC}$ ), the cycles of CAEMC countries might have become marginally more similar over time. In terms of their volatility, stronger similarities started to emerge in the course of the 1980s and the early 1990s, but the tendency reversed in the late 1990s, following internal (oil boom

${ }^{11}$ The full sets of first-order autocorrelation coefficients and standard deviations calculated for each country and each reference variable in each sub-period are reported in Carmignani (2009). 
in Equatorial Guinea) and external (volatility of international prices) shocks.

\subsubsection{Evidence from concordance indexes}

For each country $i$, Table 4 shows the sub-period average of bilateral concordance indexes (see equations (5) and (6)) between countries $i$ and all of the other CAEMC members. The last row reports the average of all the fifteen bilateral concordance indexes calculated in each sub-period (in

570 fact, due to missing data for Equatorial Guinea, the total number of bilateral concordance indexes calculated in the sub-period 1960-80 is ten). Given that there are two possible chronologies, there is a total of four sets of indexes: standard index and mean-corrected index based on the classical chronology, and standard index and mean-corrected index

575 based on the deviation chronology.

The first striking aspects emerging from the data in the table is a substantial lack of concordance of cyclical phases across CAEMC countries. The standard index ranges between 0.5 and 0.75 . However, the meancorrected index, on average barely above 0 , indicates that cycles are

580 largely independent and that the standard index is indeed inflated by the asymmetric duration of expansions and recessions, especially in the classical chronology. As a point of comparison, consider that for European countries, Harding and Pagan (2001) report standard concordance indexes around 0.9 and mean-corrected concordance indexes around 0.8

585 (somewhat lower values are reported for the only non-EMU member in the sample, the UK).

A second aspect that also appears from the table is that in general, after a decrease between the first and second sub-periods, concordance indexes tend to increase in the third and fourth sub-periods. Taking the CAEMC

590 average as a reference, it can be seen that the two mean-corrected indexes, as well as the standard index based on the deviation cycle chronology are higher in 1987-2007 than in 1960-80. The standard index based on the classical cycle chronology instead significantly drops in the second and third sub-periods, but it is on the rise in the fourth sub-period.

595 Regional averages, however, hide different patterns at the national level. While Gabon, Congo and Cameroon quite closely replicate the regional dynamics, Chad, CAR and Equatorial Guinea display a more ambiguous evolution. In particular, in CAR none of the indexes is significantly higher in 1987-2007 than in 1960-80, even though $I_{i j}^{*}$ based on the classical chronology increases remarkably during the two intermediate sub- 
Table 4. Concordance index, averages by country

\begin{tabular}{|c|c|c|c|c|c|}
\hline & & \multicolumn{2}{|c|}{ Classical cycle } & \multicolumn{2}{|c|}{ Deviation cycle } \\
\hline & & $\begin{array}{l}\text { Standard } \\
\left(I_{i j}\right)\end{array}$ & $\begin{array}{l}\text { Mean } \\
\text { corrected }\left(I_{\mathrm{ij}}^{*}\right)\end{array}$ & $\begin{array}{l}\text { Standard } \\
\left(I_{\mathrm{ij}}\right)\end{array}$ & $\begin{array}{l}\text { Mean } \\
\text { corrected }\left(I_{\mathrm{ij}}^{*}\right)\end{array}$ \\
\hline \multirow[t]{4}{*}{ CMR } & $60-80$ & 0.71429 & -0.0068 & 0.4881 & -0.01361 \\
\hline & $70-90$ & 0.60433 & 0.00359 & 0.49524 & -0.00202 \\
\hline & $80-00$ & 0.59048 & 0.06259 & 0.5619 & 0.07619 \\
\hline & $87-07$ & 0.67619 & 0.11156 & 0.5619 & 0.10159 \\
\hline \multirow[t]{4}{*}{ CAR } & $60-80$ & 0.77381 & 0.07483 & 0.46429 & -0.02154 \\
\hline & $70-90$ & 0.60606 & 0.00532 & 0.4381 & -0.05916 \\
\hline & $80-00$ & 0.55238 & 0.02449 & 0.4381 & -0.07664 \\
\hline & $87-07$ & 0.6381 & 0.07347 & 0.46667 & -0.05079 \\
\hline \multirow[t]{4}{*}{ Chad } & $60-80$ & 0.66667 & 0.04762 & 0.60714 & 0.10601 \\
\hline & $70-90$ & 0.67013 & 0.0886 & 0.52381 & 0.01831 \\
\hline & $80-00$ & 0.64762 & 0.08889 & 0.54286 & 0.02812 \\
\hline & $87-07$ & 0.71429 & 0.08707 & 0.57143 & 0.06757 \\
\hline \multirow[t]{4}{*}{ Congo } & $60-80$ & 0.77381 & 0.03288 & 0.42857 & -0.05272 \\
\hline & $70-90$ & 0.69784 & 0.06411 & 0.37143 & -0.13284 \\
\hline & $80-00$ & 0.60952 & 0.05079 & 0.48571 & -0.02902 \\
\hline & $87-07$ & 0.69524 & 0.06803 & 0.51429 & -0.00408 \\
\hline \multirow[t]{4}{*}{ Eq Guinea } & $60-80$ & & & & \\
\hline & $70-90$ & 0.58182 & -0.05455 & 0.24762 & -0.24675 \\
\hline & $80-00$ & 0.60952 & 0.01088 & 0.50476 & 0.00907 \\
\hline & $87-07$ & 0.6381 & -0.02177 & 0.44762 & -0.04807 \\
\hline \multirow[t]{4}{*}{ Gabon } & $60-80$ & 0.7381 & 0.01701 & 0.46429 & -0.02154 \\
\hline & $70-90$ & 0.63203 & 0.05051 & 0.41905 & -0.08646 \\
\hline & $80-00$ & 0.60952 & 0.0381 & 0.55238 & 0.03492 \\
\hline & $87-07$ & 0.73333 & 0.07347 & 0.5619 & 0.04354 \\
\hline \multirow[t]{4}{*}{ CAEMC } & $60-80$ & 0.733 & 0.033 & 0.490 & 0.000 \\
\hline & $70-90$ & 0.632 & 0.026 & 0.415 & -0.08 \\
\hline & $80-00$ & 0.603 & 0.045 & 0.514 & 0.007 \\
\hline & $87-07$ & 0.683 & 0.065 & 0.520 & 0.018 \\
\hline
\end{tabular}

Notes: For each country and sample period, the table reports the average of the bilateral concordance indexes (see equations (5) and (6)). The CAEMC average is obtained as the average of all the bilateral concordance indexes calculated in each sub-period. The full set of bilateral concordance indexes by pairs of countries is reported in Carmignani (2009).

periods. In Equatorial Guinea, standard indexes on average increase, but mean-corrected indexes on average decrease. Finally, in Chad, there appears to be on average an increase in the concordance with the rest of the union in terms of classical cycle, but in terms of deviation cycle concordance seems to be diminishing. 
To sum up the evidence, the bilateral concordance of cyclical phases remains relatively low throughout the observation period. However, similar to what was observed for other indicators of synchronisation, concordance marginally increases over time.

\subsection{Sensitivity and robustness}

The conclusion drawn from the analysis of the previous subsections is that 650 the synchronisation of cycles across CAEMC countries is generally low and only weakly increasing over time. As further discussed in Section 4, this means that the currency union is not as endogenously optimal as one would expect from previous empirical results. This subsection considers alternative partitions of the sample period 1960-2007 to test the robustness of the above general conclusion and to see whether any structural changes have taken place in the region that might have offset the endogeneity effect.

An increase in the synchronisation of cycles between two countries can occur through any of the following channels (see, for instance, Tapsoba,

660 2009): (i) deeper bilateral (or intra-regional) trade integration, (ii) increased similarity of macroeconomic policies, (iii) increased similarity of productive structures and (iv) increased trade intensity with the rest of the world. The endogeneity effect should operate through the first two channels, in the sense that the formation of a currency union is

665 expected to increase bilateral trade and strengthen policy harmonisation between the participating countries. However, if at the same time the countries in the currency unions face an increase in the degree of diversity of their productive structures and/or a decrease in their volume of trade with the rest of the world, then the endogeneity effect will be

670 (to some extent) neutralised. These considerations suggest splitting the sample period into sub-periods such that within each sub-period the degree of similarity of productive structures across countries and/or the intensity of trade with the rest of the world are relatively constant. In this way, the evolution of synchronisation within each sub-period is

675 driven only by changes in bilateral trade intensity and policy harmonisation. In other words, within each sub-period, the only channels at work are those through which the endogeneity effect is expected to be transmitted. One can then assess separately the strength of the endogeneity 
effect and the potential countervailing impact of structural changes in production structures and trade shocks. ${ }^{12}$

Empirically, the diversity of production structures between any two CAEMC members $i$ and $j$ at time $t$ is defined as:

$$
\mathrm{PD}_{i j t}=\frac{1}{3} \sum_{m=0}^{2}\left|v_{m, i t}-v_{m, j t}\right|
$$

where $m$ is a generic production sector (agriculture, industry or services) and $v_{m}$ denotes its GDP share. The index (7) is computed for each possible pair of CAEMC countries using data from the World Development Indicators of the World Bank. The average of (7) taken over all possible pairs of countries then measures the degree of diversity of productive structures in the CAEMC region and it is denoted by $\mathrm{PD}_{t}$. This index increases over time, ranging from 0.465 over the decade $1965-75$ to 0.694 over the decade 1995-2005. The increase, however, does not occur uniformly over time: throughout the 1970s and the 1980s the index remains well below 0.55 and it grows significantly only towards the end of the sample period.

To see to what extent the observed increase in the diversity of productive structures might have defused the endogeneity effect, the 1960-2007 period is split into sub-periods according to the values of $\mathrm{PD}_{t}$. The problem is to identify the date (or dates) at which the system moves from a low-PD regime to a high-PD regime (or vice versa). Once identified, these dates can then be used to define sub-periods characterised by a relatively stable degree of diversity of productive structures. To be able to analyse the evolution of synchronisation within sub-periods, each sub-period will have to be further partitioned into partially overlapping 'blocks' of ten years each. This in turn implies that each sub-period should be of at least fifteen years to allow at least two blocks that overlap for five years.

Hamilton (1989) proposes a dating procedure that makes use of a two-state Markov-switching regime representation of $\mathrm{PD}_{t}$. The application of this procedure yields a regime-switching date at $1992 .{ }^{13}$ Between 1960 and 1992 (low-PD regime) PD averages 0.486, whereas between 1992 and 2007 (high-PD regime) the average is 0.67 . The ten- year blocks are

12 If the sample period were split in sub-periods such that within each sub-period bilateral trade intensity and policy harmonisation are constant, then the endogeneity effect of the currency union would be voided by construction. Carmignani (2009) presents an alternative approach to the problem of controlling for structural changes in other determinants of synchronisation.

13 The switching date does not change if Equatorial Guinea is excluded from the sample. 
then $1962-72,1967-77,1972-82,1977-87,1982-92,1987-97,1992-$ 2002 and 1997-2007. The first five of these blocks fall within the low-PD regime, the last two blocks fall within the high-PD regime, whereas the block 1987-97 overlaps both regimes and is therefore regarded 725 as transitory. The measures of synchronisation described in Subsection 3.1 are recomputed for each block and averages across blocks within each of the two sub-periods. Table 5 reports, for each of the three reference variables $\Delta y, y^{\mathrm{c}}$ and $\Delta y^{\mathrm{c}}$, the average of bilateral correlations taken over all pairs of countries. Averages of the other measures of synchronisation tell 730 a very similar story and are available upon request.

To start with, consider the top part of the table, where the average bilateral correlation is shown for each variable and each block. If the increase in the diversity of productive structures across countries is the reason why monetary unification has not resulted in a sharp increase in synchronisation, then

735 one should observe fast growing correlations during the low-PD regime and weakly growing (or even decreasing) correlations during the high-PD regime. In fact, the data in the table suggest that during the high-PD regime correlations have on average marginally decreased even though the extent of this decrease varies considerably, depending on the reference vari740 able considered. This is consistent with the idea that, when productive structures have become very different across countries, business cycles have become less synchronised. However, the average correlation in the high-PD regime is generally higher than the average correlation in the low-PD regime (as the data in the bottom part of the table make clear).

745 More importantly, during the low-PD regime, correlations do not display any strong tendency to increase. On the contrary, they remain generally low and below 0.1 . In this sense, the increase in productive structure diversity across countries did not favour greater synchronisation. But even during the time when productive structures were not so different, synchronisation

750 remained low and hardly growing over time.

The other variable that might have countervailed the effect of monetary unification on synchronisation is total trade integration (TT) with the rest of the world. As discussed in previous works (see, for instance, Baxter and Kouparitsas, 2005; Tapsoba, 2009), larger trade flows with the rest of the 755 world can increase the bilateral synchronisation of cycles between countries $i$ and $j$ over and above any effect due to bilateral trade. Possible transmission channels of this effect include greater opportunities for technological spillovers and/or a higher likelihood of experiencing similar global shocks. In this sense, TT might have been an obstacle to greater synchronisation in the region only to the extent that it has decreased over 
Table 5. Average of bilateral correlations over ten-year blocks and sub-periods

\begin{tabular}{|c|c|c|c|c|c|c|c|c|}
\hline & \multicolumn{5}{|c|}{ Low-PD period } & \multirow{2}{*}{$\frac{\text { Transition }}{1987-97}$} & \multicolumn{2}{|c|}{ High-PD period } \\
\hline & $1962-72$ & 1967-77 & $1972-82$ & 1977-87 & 1982-92 & & $1992-02$ & 1997-07 \\
\hline$\Delta y$ & 0.142 & 0.042 & 0.034 & 0.071 & 0.098 & 0.171 & 0.048 & -0.020 \\
\hline$y^{c}$ & 0.137 & -0.003 & 0.058 & 0.065 & 0.003 & 0.065 & 0.144 & 0.038 \\
\hline \multirow[t]{3}{*}{$\Delta y^{c}$} & 0.108 & 0.013 & 0.022 & 0.002 & -0.006 & 0.072 & 0.064 & 0.046 \\
\hline & \multicolumn{5}{|c|}{ Low-PD period } & \multicolumn{3}{|c|}{ High-PD period } \\
\hline & \multicolumn{3}{|c|}{$1962-92$} & \multicolumn{2}{|l|}{$1977-92$} & \multicolumn{3}{|c|}{$1992-07$} \\
\hline$\Delta y$ & \multicolumn{3}{|l|}{0.040} & \multicolumn{2}{|l|}{0.012} & \multicolumn{3}{|l|}{0.113} \\
\hline$y^{c}$ & \multicolumn{3}{|l|}{0.037} & \multicolumn{2}{|l|}{0.027} & \multicolumn{3}{|l|}{0.117} \\
\hline$\Delta y^{c}$ & \multicolumn{3}{|l|}{-0.007} & \multicolumn{2}{|l|}{-0.022} & \multicolumn{3}{|l|}{0.037} \\
\hline
\end{tabular}

Notes: The top part of the table shows the average of bilateral correlations for each block of ten years. The bottom part of the table shows the average of bilateral correlations for the two sub-periods corresponding to low-PD regime (1962-92) and high-PD regime (1992-07) and for a spell of fifteen years (1977-92) prior to regime switch.

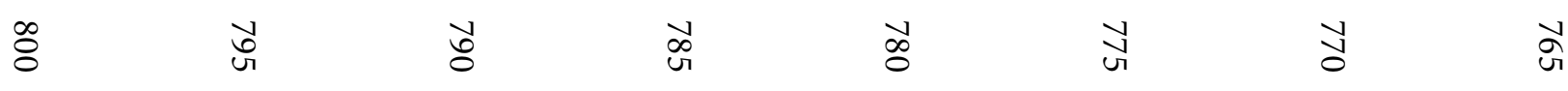


time, reflecting a progressive isolation of CAEMC countries from global trade links. However, this does not seem to be the case. For each pair of countries $i$ and $j$, TT can be simply measured as the sum of exports and imports of $i$ plus the sum of exports and imports of $j$ divided by the sum of the GDP of $i$ and $j$. Taking averages over all pairs of CAEMC countries, an average of trade intensity of the CAEMC region is then obtained. This average increases from 1.403 in $1965-75$ to 1.853 in 1995-2005. With the exception of a few years before the 1994 devaluation, TT increases steadily throughout the sample period. Because trade inten810 sity is not decreasing over time, one can reject the idea that synchronisation was kept low by negative trade shocks. Even so, it is interesting to analyse possible regime switches in the TT series. The only significant change in regime occurs in 1994, most likely in association with the devaluation of the CFA franc. Following that devaluation, the CAEMC also started a 815 series of reforms to promote intra-regional trade and foster regional economic integration. Therefore, one wonders to what extent the switch from low-TT to high-TT regimes and the reforms introduced after the devaluation affected synchronisation. The rest of the subsection is devoted to answering that question.

820 To some extent, the data reported for the period 1987-2007 should already capture any possible effect from devaluation and reforms. Moreover, the partition used in Table 5 (with a switch date at 1992) is very similar to the one that would be obtained by imposing a switch date at 1994. The evidence presented in that table is therefore most likely to provide a good representation of 825 possible changes in the patterns of synchronisation caused by the re-alignment of the exchange rate and the reforms. Nevertheless, as a further sensitivity check, correlations and concordance indexes have been recomputed for the sub-period 1994-2007 (and are available upon request). It turns out that they are quite similar to those reported for the sub-

830 period 1987-2007. Indeed, the only significant change is observed with respect to the average correlation of $y^{c}$. Its average between 1994 and 2007 is 0.1, thus higher than the average computed for 1987-2007 (0.047; see Table 2). However, it must be noted that this average of 0.1 is still lower than the average of the sub-period 1980-93 (0.138) and is only marginally

835 higher than the average of the first sub-period 1960-80. This confirms that the devaluation and the post-1994 reforms did not cause a structural break in the evolution of synchronisation. ${ }^{14}$

${ }^{14}$ A further confirmation of this conclusion comes from the fact that there is no structural break in the time series of the standard deviation of $y^{c}, \Delta y^{c}$ and $\Delta y$ across countries. If the 


\section{Discussion}

A common pattern seems to emerge from the statistical dimensions investigated in Section 3: synchronisation is low, but somewhat increasing over time. Thus, what do these results imply for the endogenous OCA hypothesis?

To answer this question, the results of Section 3 must be compared against some benchmark. For this purpose, we consider the meta-estimates provided by Rose $(2004,2008)$ : (i) the formation of a currency union is expected to increase intra-union trade by between 30 and $90 \%$ in the longterm, even though for the EMU the trade effect ranges between 8 and 23\%; (ii) each $1 \%$ increase in trade between two countries increases the bilateral correlation coefficient of detrended outputs by 0.02 . However, there are three caveats in deriving benchmarks for the CAEMC from these two sets of meta-estimates. One is that most of the papers surveyed in the meta-analysis focus on the EMU, which is structurally a very different monetary union from the CAEMC. The second caveat is that the time frame of the meta-estimated effects is not explicit. The final caveat is stated explicitly by Rose (2004) in the following terms: "[Thus] it would be unreasonable for anyone to have too much confidence in the meta-analytic estimate of the effect of currency union on trade'.

Keeping all caveats in mind, however, an increase in the bilateral correlation coefficient of detrended series between 0.2 and 0.5 can be set a reasonable conservative benchmark. The estimates provided in Section 3 seem to put the CAEMC below this benchmark, thus confirming that the observed increase in synchronisation in the region is marginal. In this respect, it can be argued that the endogenous OCA hypothesis does not fully fit the CAEMC data. That is, the CAEMC currency union does not seem to be as endogenously optimal as would be expected from the result of previous panel and cross-country estimates. Nevertheless, there is some degree of endogeneity as the growing correlations of output fluctuations, the increasing similarities of the statistical properties of cycles and a stronger concordance of cyclical phases over time indicate.

The question that then remains to be discussed is what prevents the CAEMC from being a fully endogenous OCA. As noted in Section 3.3, the increase in diversity of productive structures has somewhat reduced

post-1994 reforms had effectively increased synchronisation to a significant extent, then annual series of the standard deviation should exhibit a break around 1994. Various versions of Chow's test reject this hypothesis. 
synchronisation, but it cannot take all the blame for the weakness of the endogeneity effect. The same is true for structural changes in total trade intensity with the rest of the world. What really explains the lack of endogeneity is probably the fact that the two main channels through which a monetary union becomes endogenously optimal, namely the intensification of intra-regional trade and the harmonisation of policies across countries, are not fully at work in the CAEMC. Intra-regional trade in current dollars was US\$149.26 millions in 1980. By 2007 it reached US\$ 608.62 millions, with an average annual growth of around $11 \%$.

890 However, total international trade of CAEMC countries went up from US\$ 7444.13 millions to US\$ 42808.3 millions over the same period of time. This is equal to an average annual increase of around $17 \%$. The proportion of regional trade in total international trade has therefore decreased from a mere $2 \%$ to an even smaller $1.4 \% .{ }^{15}$ This in turn reflects

895 the persistence of high non-tariff barriers, most notably the lack of physical connectivity across countries and the poor state of transport infrastructures (see, for instance, UNECA, 2007). In a similar vein, the CAEMC did not introduce a rigorous framework for policy harmonisation in the region until 1997. This certainly goes some way towards explaining the 900 lack of convergence of macroeconomic policies across union members. Between 1970 and 2006, the cross-country standard deviation of the budget balance has gone up from 3.65 to 12.33 , mostly as a result of increased dispersion in revenues (while dispersion in expenditures is decreasing since 1998). Interestingly, monetary variables also display

905 growing dispersion across countries: from 3.54 to 14.37 for the money growth rate and from 0.86 to 2.47 for the inflation rate. The fact that monetary variables do not converge in spite of a centralised monetary policy is indicative of persistent asymmetries in monetary policy transmission mechanisms. ${ }^{16}$

\section{Conclusions and directions of future research}

From a policy perspective, this paper has implications both for the design of CAEMC policy and institutions and for the process of monetary unification in Africa. With respect to the former, CAEMC countries must strengthen policy harmonisation and physical connectivity in order to

${ }^{15}$ Trade data are taken from IMF (2008).

${ }^{16}$ For a systematic analysis of macroeconomic policy convergence in the region, see 
activate the channels through which business cycles can become more synchronised and hence maximise the benefits from monetary integration. A revision of the existing set of convergence criteria might therefore be necessary. Furthermore, countries should take advantage of buoyant oil (and other natural resources) revenues to strengthen the public investment in infrastructures, particularly in relation to regional projects of transport development.

With respect to monetary unification in Africa, the CAEMC experience shows that currency areas are not necessarily endogenously optimal even after a long period of time. Nevertheless, they can be sustained in spite of this lack of optimality, and they do tend to generate somewhat more synchronised cycles over time. Therefore, it is probably not necessary that countries fully meet the optimality criteria before new unions are formed, or even before a continental union is envisaged. However, the unification process ought to be gradual, and attention must be devoted to the design of institutional arrangements for monetary and exchange rate policy, to the consolidation of political will and to the preparation of a credible framework to encourage de facto convergence of macroeconomic policy instruments.

From a research perspective, four issues to be explored in future work are worthy of mention. First, the statistical analysis of this paper should be extended to the other regional groupings in Africa. Indeed, even if they have not yet achieved the stage of monetary unions, several African RECs are making considerable progress in terms of trade integration and policy harmonisation frameworks. It would be interesting, therefore, to see whether such progress is making business cycles more synchronised. Second, future research should analyse whether or not there exist clusters of countries, within or across the borders of existing RECs, which already configure as OCAs and/or display the characteristics of fully endogenous OCAs. If such clusters existed, then one could envisage a process whereby monetary unions are first formed in those clusters, and then other countries join in after a gradual transition. Third, for the specific case of the CAEMC, it will be interesting to study the cyclical characterisation of macroeconomic policies. This investigation can be done at two levels. At the national level, the analysis should establish whether fiscal and monetary policy indicators are pro-cyclical, acyclical or anti-cyclical. At the regional level, the focus should be on the common monetary policy to understand whether it follows the cycle of any CAEMC member in particular. This would facilitate the assessment for each country of the costs and benefits associated with the weak 
synchronisation of business cycles. In fact, given that the CFA franc is pegged to the Euro, one can imagine that the CAEMC countries that benefit the most from the centralised monetary policy are those whose business cycle is more synchronised with the European business cycle. At

965 least, this would be true to the extent that the European Central Bank bases its monetary policy on the European business cycle. Fourth, the statistical methodology could be extended to perform a formal test of synchronisation in CAEMC countries versus other country groupings (in Africa and/or outside Africa). The test would require the creation of country

970 groupings whose members are selected at random and/or on the basis of criteria other than participation in the same currency union. A measure of synchronisation in these groupings should then be computed and a distribution derived. This distribution can then be used for a statistical inference on the significance of the degree of synchronisation observed in the

975 CAEMC group.

\section{Acknowledgements}

980 I would like to thank James Laurenceson and KK Tang, two anonymous referees, the editor Michael Bleaney and participants in the 2008 African Economic Conference (Tunis, 12-14 November, 2008) for very helpful comments. Dorothy Schepps provided valuable editorial assistance. I am solely responsible for any remaining errors and inconsistencies.

\section{References}

990 Agbeyegbe, T. D. (2008) 'On the Feasibility of a Monetary Union in the Southern Africa Development Community', International Journal of Finance and Economics, 13: 135-204.

Artis, M., M. Marcellino and T. Proietti (2004) 'Dating the Euro-Area Business Cycle', Oxford Bullettin of Economics and Statistics, 66: 537-65.

Artis, M., M. Marcellino and T. Proietti (2005) 'Characterizing Business Cycles for Accession Countries', Journal of Business Cycle Measurement and Analysis, 2: 741.

Bangake, C. (2008) 'Exchange Rate Volatility and Optimum Currency Area: Evidence from Africa', Economics Bulletin, 6: 1-10.

Barro, R. and S. Tenreyro (2007) 'Economic Effects of Currency Unions', Economic Inquiry, 45: 1-23. 
Baxter, M. and R. King (1999) 'Measuring Business Cycles: Approximate Band-Pass Filters for Economic Time Series', Review of Economics and Statistics, 81: 575-93.

Baxter, M. and M. Kouparitsas (2005) 'Determinants of Business Cycles Co-movement: A Robust Analysis', Journal of Monetary Economics, 52: 113-57. Belke, A. (2007) 'Endogenous Optimum Currency Areas and the Blend of Sectors - on the Determinants of Business Cycle Correlation across European Regions', Journal of Economic Integration, 22: 26-49.

Bry, G. and C. Broschan (1971) Cyclical Analysis of Time Series: Selected Procedures and Computer Programs. New York: NBER.

Buigut, S. K. and N. T. Valev (2005) 'On the Adequacy of Monetary Arrangements in Sub-Saharan Africa', The World Economy, 28: 349-73.

Burns, A. F. and W. C. Mitchell (1946) Measuring Business Cycles. New York: NBER.

Carmignani, F. (2006) 'The Road to Regional Integration in Africa: Macroeconomic Convergence and Performance in COMESA', Journal of African Economies, 15: 212-50.

Carmignani, F. (2009) Endogenous Optimal Currency Areas: the Case of the Central African Economic and Monetary Community, School of Economics Discussion Paper No. 390, School of Economics, The University of Queensland (available on line at http://www.uq.edu.au/economics/abstract/ 390.pdf).

Coe, D. T. and E. Helpmann (1995) 'International R\&D Spillovers', European Economic Review, 39: 859-87.

Corsetti, G. and P. Pesenti (2002) Self-validating Optimum Currency Areas, NBER Working Paper 8783.

Darvas, Z. and G. Szapáry (2008) 'Business Cycle Synchronization in the Enlarged EU', Open Economies Review, 19: 1-19.

Fidrmuc, J. (2004) 'The Endogeneity of the Optimum Currency Area Criteria, Intra-industry Trade, and EMU Enlargement', Contemporary Economic Policy, 22: $1-12$.

Fielding, D. and K. Shields (2005) 'The Impact of Monetary Union on Macroeconomic Integration: Evidence from West Africa', Economica, 72: 683704.

Fielding, D., K. Lee and K. Shields (2004) 'The Characteristics of Macroeconomic Shocks in the CFA Franc Zone', Journal of African Economies, 13: 488-517.

Frankel, J. and A. Rose (1998) 'The Endogeneity of Optimal Currency Area Criteria', Economic Journal, 108: 1009-25.

Hamilton, J. (1989) 'A New Approach to the Economic Analysis of Nonstationary Time Series and the Business Cycle', Econometrica, 57: 357-84.

Harding, D. and A. Pagan (2001) Extracting, Using and Analysing Cyclical Information, MPRA Paper 15, University Library of Munich, Germany. 
Harding, D. and A. Pagan (2006) 'Synchronization of Cycles', Journal of Econometrics, 132: 59-79.

Hodrick, R. and E. Prescott (1997) 'Postwar U.S. Business Cycles: an Empirical Investigation', Journal of Money, Credit, and Banking, 29: 1-16.

Houssa, R. (2008) 'Monetary Union in West Africa and Asymmetric Shocks: a Dynamic Structural Factor Model Approach', Journal of Development Economics, 66: 199-224.

IMF - International Monetary Fund (2008) Direction of Trade Statistics. Washington, DC.

1050

Karras, G. (2007) 'Is Africa an Optimum Currency Area? A Comparison of Macroeconomic Costs and Benefits', Journal of African Economies, 16: 234-58.

Khamfula, Y. and H. Huizinga (2004) 'The Southern African Development Community: Suitable for a Monetary Union?', Journal of Development Economics, 73: 699-14.

Proietti, T. (2005) 'New Algorithms for Dating the Business Cycle', Computational Statistics and Data Analysis, 49: 477-98.

Ravn, M. and H. Uhlig (2002) 'On Adjusting the Hodrick-Prescott Filter for the Frequency of Observations', Review of Economics and Statistics, 84: 371-75.

Rose, A. (2000) 'One Money, One Market: Estimating the Effect of Common Currencies on Trade', Economic Policy, 30: 9-45.

Rose, A. (2004) A Meta-analysis of the Effect of Common Currencies on International Trade, NBER Working Paper 10373.

Rose, A. (2008) 'EMU, trade and business cycles synchronization', Mimeo, Haas School of Business, University of California, Berkeley.

Savva, C., K. Neanidis and D. Osborn (2007) Business Cycle Synchronization of the Euro Area with the New and Negotiating Member Countries, University of Manchester, Centre for Growth and Business Cycle Research, Working Paper 091.

Tapsoba, S. J. (2009) 'Trade Integration and Business Cycle Synchronicity in Africa', Journal of African Economies, 18: 287-318.

UNECA - United Nations Economic Commission for Africa (2004) Assessing Regional Integration in Africa. Addis Ababa Ethiopia.

1070

UNECA - United Nations Economic Commission for Africa (2007) Convergence Economique en Afrique Centrale. Yaounde, Cameroon: Bureau Sous-regional pour l'Afrique Centrale. 